\title{
O ACERVO DOCUMENTAL DAS ESCOLAS QUE COMPÕE O CENTRO DE MEMÓRIA DA EDUCAÇÃO DO SUL DE SANTA CATARINA (CEMESSC) - DIAGNÓSTICO E ORIENTAÇÕES PARA CONSERVAÇÃO E PRESERVAÇÃO
}

Cintia Gonçalves Martins ${ }^{1}$

Filipe Ricardo da Cruz ${ }^{2}$

Selma Tereza Leepkaln Dassil $\left.\right|^{3}$

Taise Machado Figueiredo ${ }^{4}$

A história da educação enquanto historiografia e/ou pesquisa vem nos últimos anos, mais precisamente a partir da década de 1980-90 passando por uma série de mudanças. Estes estudos tem valorizado o patrimônio histórico escolar, na tentativa de reconstruir a história destas instituições. Como parte deste compromisso, vê-se que na Universidade do Extremo Sul Catarinense (UNESC) no ano de 2001, fora instituído o Grupo de Pesquisa História e Memória da Educação (GRUEHME) vinculado ao Programa de Pós-Graduação em Educação (PPGE UNESC). No entanto, a partir da atuação do GRUPEHME após pesquisas no campo da educação, no que tange escolas do sul do estado (SC). Viu-se a necessidade de implantar um Centro de Memória da Educação do Sul de Santa Catarina (CEMESSC), a fim de, salvaguardar e/ou preservar os acervos escolares de escolas públicas da rede estadual de ensino desta respectiva região, isto de 2009 à 2013. Como continuidade, no ano de 2015, aprouve como necessidade a devolutiva do CEMESSC nas escolas envolvidas, e, semelhantemente uma espécie de pesquisa para diagnosticar a situação atual dos acervos escolares, uma vez que a equipe ao recolher a documentação nos anos de 2010-2013, para digitalização, percebeu-se problemas nestes materiais.

A partir desta discussão, podemos elencar que como objetivos basilares para esta pesquisa em andamento (2015-2016), se tem a ideia de diagnosticar a situação dos acervos documentais das escolas envolvidas no CEMESSC; não obstante, sensibilizar as escolas sobre a preservação do patrimônio educativo;

\footnotetext{
${ }^{1}$ Mestranda em Educação, PPGE - UNESC,cintiamartins@unesc.net.

${ }^{2}$ Graduando em História, UNESC, filipericardone@live.com.

${ }^{3}$ Restauradora do CEDOC - UNESC, slt@unesc.net.

${ }^{4}$ Auxiliar de Restauro do CEDOC - UNESC, taise_figueiredo@unesc.net.
} 
outrossim, orientar as escolas (e parte de sua comunidade) acerca da conservação e preservação do acervo documental (objetivo que se dá em parceria com o CEDOC: Centro de Memória e Documentação da UNESC); e, por último e não menos importante, dar visibilidade ao CEMESSC na região sul de Santa Catarina. Estes objetivos corroboram e se incorporam ao longo deste texto como pontos fundamentais, ou seja, estão intrínsecos à metodologia do trabalho de pesquisa, no que veem construindo um cenário de maior contato e até diria que diálogo do CEMESSC com as respectivas escolas envolvidas neste.

No que concerne ao quadro teórico desta pesquisa, pode-se dizer que tem-se três autores que estão sendo mais utilizados, contribuindo com suas pesquisas para a experiência e discussão deste trabalho. Entre estes autores que dão base para a pesquisa, destacamos a Historiadora brasileira e Doutora em Educação Lilia lanke Leite; a Historiadora portuguesa e Doutora em Ciências da Educação Maria João Mogarro; a historiadora; a Historiadora da Unicamp e Doutora em História da Educação Maria Cristina Menezes; e, o Historiador francês Roger Chartier.

Neste viés, LEITE (s/d) destaca que dentre a história da educação, no tocante dos arquivos escolares, a situação destes arquivos é constantemente preocupante, onde o principal motivo seria o respaldo em: arquivo limitado destes documentos de comprovação da vida escolar. Semelhantemente, MOGARRO (2005) contribui para a perspectiva de que há uma construção e consolidação de uma memória educativa, ou até identidade regional, local, aprofundando o vinculo das escolas aos itinerários históricos, valorizando então a cultura escolar e seus percursos institucionais, e, vinculando a população / comunidade ao passado escolar, no que remete ao sentimento de pertença de entidade coletiva. Ainda assim, MENEZES (2011) enfatiza que pesquisa, pesquisadores, grupos / subgrupos, projetos, ações de preservação, enfim, devem de proporcionar um campo fértil para a pesquisa no âmbito da história da educação, fomento de novos saberes, entretanto, enriquecendo a relação social com a cultural das respectivas escolas. Não obstante, CHARTIER (2002) elenca sobre a digitalização que há uma necessidade de cidadãos e herdeiros do passado exigir o não desaparecimento dos objetos originais, mantendo possibilidades de acesso aos textos como foram impressos e lidos na sua época. 
Por meio destes embasamentos teóricos coube-nos uma série de reflexões, entre elas, a ideia de contrapor-se ao descaso e/ou desusos de documentos escolares; também, de gradativamente construir ou reconstruir uma memória acerca destes educandários; de igual modo, tornar estas fontes históricas permeáveis no campo da pesquisa, sobremaneira que isto também possa respaldar no ensino e/ou extensão de conhecimento atinente a temática; e, ainda assim, nada na maré contrária a uma cultura de descarte, ainda que haja digitalização de documentos, sendo isto um desafio e, portanto, um trabalho paulatino. Deste modo, tem-se a metodologia desta pesquisa, que possui pelo menos oito momentos. Quais são, primeiro: a preparação do bolsista a partir de referenciais teóricos sobre conservação e preservação do patrimônio educativo - alguns já citados no parágrafo anterior. Segundo: realização de um diagnóstico das circunstâncias das escolas envolvidas no CEMESSC localizadas nas micro regiões do sul de Santa Catarina que correspondem a Associação dos Municípios da Região Carbonífera (AMREC), Associação dos Municípios da Região do Extremo Sul Catarinense (AMESC), e, Associação dos Municípios da Região de Laguna (AMUREL).

Terceiro: entrega dos CD ROOM (individualmente e personalizados) com os documentos e produções digitalizados das respectivas escolas. Quarto: demonstração sobre a consulta ao acervo do CEMESSC em meio virtual. Quinto: das orientações práticas sobre a conservação e preservação do acervo documental destas escolas, isto em parceria com o CEDOC. Sexto: escrita processual de um artigo científico. Sexto: apresentação dos resultados da presente pesquisa em eventos da área de história da educação e patrimônio educativo. E, sétimo: envio de artigos para periódicos da mesma área. Observando que estes três últimos momentos (momento 6, 7 e 8) estão em andamento. Enquanto dos momentos 2 ao 5 são metodologias executadas nas escolas, isto nas visitas, ou melhor, retorno devolutiva do CEMESSC às mesmas.

A equipe formada pelo bolsista de iniciação científica, membros do CEDOC e professores/as pesquisadores/as do GRUPEHME ao chegar às escolas, mediante uma solicitação prévia, apresentam o CEMESSC em suas dimensões digitais, a forma como foi construído e funcionamento, perspectivas patrimoniais relacionando às pesquisas que vem sendo desenvolvidas a partir do acervo documental disponibilizados, bem como noções básicas de preservação conservação dos documentos escolares. Os documentos históricos dos 
educandários, como os de outras instituições, geralmente são escassos e são considerados "velhos" numa cultura de descarte, sabendo dos prejuízos deste tipo de cultura para a história e memória da educação, são dadas orientações pelos membros do CEDOC. A equipe, especializada em preservação e restauração de documentos, traz exemplos de documentos prejudicados pelo descaso e oferecer, dentro de um viés dialógico, dinâmicas e oficinas para os/as professores/as e equipes diretivas.

Lembrando que esta pesquisa advém primeiramente do GRUPEHME que desde 2001 tem pesquisado a campo e feito revisões bibliográficas acerca da história e memória da educação, mais propriamente no sul catarinense, por meio de bolsistas, e pesquisadores - educadores especializados, alguns mestres e/ ou doutores. E, que posteriormente em 2009 houve a implantação do CEMESSC, e escolha de vinte e sete (27) escolas para pesquisa acerca da mesma temática. Escolha esta que se deu no critério de escolas mais antigas das três regiões: onze escolas da AMREC, onze da AMESC, e onze da AMUREL. Ainda assim, usufruindo de documentos escolares mais antigos como da década de 1930, 1940, 1950, quando a escola possuía, mas, limitando-se destes mais antigos até da década de 1980, devido a demanda de tempo a ser utilizado como pesquisa, autorização da Secretaria da Educação de Santa Catarina, consulta ao Comitê de ética da Unesc, seleção de documentos, digitalização de documentos, redação de históricos das escolas, criação de um site in locus com auxilio do TI (Tecnologia da Informação da Unesc), criação de um banco de dados, virtual e em CD ROOM, enfim.

Dentro destas pesquisas, percebeu-se a necessidade de estabelecer um contato com as escolas envolvidas ao CEMESSC no que concerne aos documentos escolares, na condição de acervos documentais em sua maioria comprometidos com a preservação destes em seu aspecto físico (como material impresso em situações precárias de armazenamento) ou em sua situação informatiza (documentos deteriorados devido ausência de preservação). Neste sentido aprouve um projeto de iniciação científica pelo Programa de Bolsas de Iniciação Científica (PIBIC) nos anos de 2015-16 (Edital n\} 18/2015), Unesc, a fim de não só salvaguardar estes documentos, mas, sensibilizar a comunidade escolar acerca destes, como pertencentes e subjacentes a história - historiografia da instituição escolar.

Em termos de resultados e discussões acerca deste projeto, as visitas aos educandários estão baseadas na ideia de Chartier (2002) que se contrapõe à 
renegação dos documentos escolares após a prática de digitalização realizada. A partir do processo de implantação do CEMESSC é solicitado que cada escola responda um questionário que busca diagnosticar (outro objetivo do projeto) a situação dos acervos documentais das escolas envolvidas: questionando o local de acondicionamento; se o profissional está apto para o trabalho de preservação dos mesmos; sobre a cultura de descarte de documentos; se estes documentos são higienizados e/ou restaurados; se são usufruídos pelos docentes em sala de aula etc. Permeando a concepção de não ocasionar nestas escolas o desaparecimento dos objetos originais - documentos, portanto, valorizando a memória destas escolas, em contrapartida ao esquecimento.

Como resultados da metodologia proposta, as escolas disponibilizam no geral em torno de uma hora para estas discussões/apresentações que permeiem o CEMEESC. Inicialmente, por ocasião da visita, é apresentando o CEMESSC à comunidade escolar; posteriormente, são realizadas orientações de conservação e preservação dos documentos pelos membros do CEDOC; por fim, uma visita aos locais onde estão guardados os documentos a fim de fotografá-los, o que ocasiona a captção de imagem acerca das reais (ou parciais) circunstancias deste acervos. A partir das escolas já visitadas podemos afirmar, o quão tem sido interativo esse retorno. Em termos de espaço para a realização da atividade, as escolas têm cedido as salas, auditórios ou salas de aula mais amplas e confortáveis, que permitam o acesso à internet e o uso de data show. Até o momento, neste início de semestre, 2016, das 27 escolas, foram visitadas 10 escolas, 7 pertencentes a região da AMREC e 2 à região da AMESC, e 1 à região da AMUREL. Dentre estas, em ordem cronológica (de novembro de 2015 a fevereiro de 2016) estão às escolas: E.E.B Salete Scotti dos Santos, da cidade de Içara/SC; E.E.B. Angelo Izé, Forquilhinha/SC; E.E.F. Visconde de Taunay, Lauro Muller/SC; E.E.B. Julieta Torres Gonçalves, Nova Veneza/SC; E.E.B. Udo Deeke, Treviso/SC; E.E.B. José do Patrocínio, Siderópolis/SC; E.E.B. Princesa Isabel, Morro da Fumaça/SC; E.E.B Castro Alves, Araranguá/SC; EEB Professora Eulina Heleodoro Barreto, Imaruí/SC; e, EEB Manoel Gomes Baltazar, Maracajá/SC.

No que concerne este contato com a comunidade escolar, podemos observar que as escolas têm demonstrado certo (des) conhecimento sobre a importância dos acervos históricos para a memória da educação e dos educandários. Ao visitarmos os arquivos escolares tangíveis, notamos geralmente 0 
descaso para com os documentos e objetos históricos, que vai desde o modo de armazenamento, passando pela falta de um ambiente próprio para a salvaguarda dos documentos (luminosidade/umidade), chegando até a falta de um profissional que esteja apto para organizar - proporcionar o acondicionamento adequado para esse tipo de acervos, em termos de higienização, conservação, restauração, enfim, estas características que perpassam as noções básicas de preservação documental. Positivamente, encontramos algumas escolas com sala apropriadas para os documentos, algumas com uma organização maior, em ordem cronológica, alfabética e /ou numérica. Em uma escola constatamos que além de terem estes cuidados a profissional responsável pelo acervo mencionou ter realizado um curso oferecido pela UNESC que proporcionou o acesso ao conhecimento de como sistematizar os documentos por meio de um catálogo.

Acerca mais especificamente dos questionários, podemos inferir que de modo geral, diria que mais que $50 \%$ das escolas, as respostas contidas nos questionários não corroboram com a visita in locus às escolas, muito menos com a captação das imagens concernentes aos acervos escolares e suas dimensões de armazenamento, profissional responsável, formato organizacional, enfim. Porquanto, geralmente percebemos alguns discursos que giram em torno do descarte, em especial na citação de uma espécie de possibilidade de alguns casos poderem incinerar os documentos; não obstante, a ideia de restauro se deu de modo praticamente genérico em dizer que não usufruem de tal prática, salvo uma escola que respondeu usufruir.

No que confere as digitalizações, $100 \%$ das escolas que até então responderam os questionários disseram não haver esta prática, o que já de certa maneira menos viabiliza a questão da pesquisa e/ou plausível manuseio dos matérias na comunidade escolar e/ou comunidade externa. Falando em manuseio, acerca de utilizar dos documentos escolares para fins de atividades pedagógicas cerca de $60 \%$ inferiu que utiliza, e $40 \%$ que não utiliza, mas, isto vai além devido respostas fomentarem aspectos esporádicos de atividades com documentos, ou respostas superficiais que não necessariamente confirmem esta utilização de documentos como material didático em sala de aula. Dos equipamentos apropriados, também $100 \%$ das escolas responderam não fazer uso de equipamentos apropriados para o manuseio e/ou cuidado com acervos documentais, este ponto, já poderia ser uma espécie de base para refletirmos se realmente há um 
espaço de armazenamento, digitalização, preservação, restauração, utilização em aula, enfim, as condições destes documentos já se dão comprometidas devido a não utilização de equipamentos apropriados que seriam o mínimo para salvaguardar, devido um contato constante com eles, em termos de higienização, arquivamento, pesquisas, utilização, e assim por diante. Já que algumas questões se deram no percentual de $100 \%$, outra que se assemelhou foi a que corresponde ao descarte de documentos, onde todas responderam usar desta prática de descarte. Mas, a questão é, como esta prática é utilizada, e quem que medida estes acervos descartados são digitalizados (qual nenhuma das escolas respondeu praticar digitalização), ou que critérios respaldam na coerência de descarte acerca das noções básicas de preservação documental?

O trabalho de retorno ou em outros termos de devolutiva às escolas (trabalho ainda em andamento), faltando ainda a visita às 17 escolas restantes. Entretanto, constatamos nas escolas já visitadas (10 escolas) que os profissionais da educação em sua maioria não conhecem os acervos escolares, não compreendem a importância que os mesmos têm para as pesquisas em história da educação, no que se refere à instituição e à comunidade escolar, e muitos deles não possuem uma formação específica na área de documentação. Neste viés, os documentos em alguns educandários estão gravemente ameaçados pela cultura do descarte, talvez este seja um dos pontos mais latentes da pesquisa. Não obstante, percebemos de modo geral uma incoerência acerca das respostas obtidas nos questionários respondidos pelas escolas, frente a visita in locus do CEMESSC e captação dos acervos escolares destas respectivas.

Todavia, em algumas escolas observamos a preocupação de alguns profissionais, sendo esta preocupação em certa medida interdisciplinar (ora um profissional da história, ora um da educação física, ora outro mais da gestão escolar), entretanto, observaram-se algumas salas específicas para armazenamento dos documentos. Encontramos uma parcela de escolas que já estão sensibilizadas com a importância da preservação. Portanto, acreditamos ser necessário o conhecimento e a sensibilização junto à comunidade escolar em relação ao patrimônio histórico escolar, a fim de garantir sua preservação, não somente isto, mas, a construção de uma sensibilização acerca do vasto acervo documental destes educandários, sensibilização em torno da comunidade escolar, em diálogo com a historiografia recente, com pesquisas contemporâneas, com a universidade, em 
outras palavras, uma (re) construção da história da educação, sobretudo, da conscientização dos que estão envolvidos neste contesto conflituoso, complexo e desafiador.

\section{REFERÊNCIAS}

CENTRO DE MEMÓRIA DA EDUCAÇÃO DO SUL DE SANTA CATARINA CEMESSC. Disponível em: http://www.bib.unesc.net/muesc/muni_07.php. Acesso em 30 Mar. 2016.

CHARTIER, Roger. Os desafios da escrita. São Paulo, UNESP, 2002.

COSTA, Marli de Oliveira; RABELO, Giani. Centro de Memória da Educação do Sul de Santa Catarina (CEMESSC) e os estudos sobre a cultura escolar. Educação Unisinos. V.18, n.1. $2014 \quad$ Disponível http://revistas.unisinos.br/index.php/educacao/article/view/edu.2014.181.05. Acesso em: 30 Mar. 2016.

LEITE, Lilian lanke. Arquivo Morto ou Arquivo Histórico-Educacional: Qual o lugar da memória da/na escola? Área temática: profissionalização docente e formação. p. 1977-1989.

MENEZES, Maria Cristina. Descrever os Documentos - Construir os Inventários Preservar a Cultura Material Escolar. Rev. bras. hist. educ. Campinas-SP, v. 11, n. 1 (25), p. 93-116, jan/abr 2011.

Preservação do Patrimônio Histórico Institucional: a importância dos acervos escolares nos estudos da instituição. Universidade Estadual de Campinas. p. $445-455$.

MOGARRO, Maria João. Os arquivos escolares nas instituições educativas portuguesas: preservar a informação, construir a memória. Pro-posições, v. 16, n. 1 (46), p. 103-116, jan/abr. 2005.

VALENTE, W. R. Arquivos escolares virtuais: considerações sobre uma prática de pesquisa. Revista Brasileira de História da Educação, 10 (1): p. 175-192, 2005.

VIDAL, Diana Gonçalves; SILVA, Vera Lucia Gaspar. Por uma História da Sensorial da Escola e da Escolarização. In: CASTRO, César Augusto (org.) Cultura Material Escolar: a escola e seus artefatos (MA, SP, PR, SC e RS, 1870 - 1925). São Luís: EDUFMA: Café \& Lápis, 2011. 